\title{
Alcohol-related liver disease: do weather and daylight level matter or is there a paradoxical good side of global warming?
}

\author{
Nathalie Ganne-Carrié , $^{1,2}$ \\ ${ }^{1}$ AP-HP, Hôpitaux Universitaires Paris Seine-Saint Denis, Jean Verdier Hospital, Liver Unit, Bondy, France; ${ }^{2}$ University Paris 13 , Sorbonne Paris \\ Cité, équipe labellisée Ligue Contre le Cancer, F-93000 Bobigny, France; ${ }^{3}$ INSERM UMR-1162, Functional Genomics of Solid Tumours, F-75010, \\ Paris, France \\ Correspondence to: Nathalie Ganne-Carrié. Liver Unit, AP-HP, Hôpitaux Universitaires Paris Seine-Saint Denis, Jean Verdier Hospital, Bondy, \\ France. Email: nathalie.ganne@aphp.fr. \\ Provenance: This is an Invited Editorial commissioned by Section Editor Dr. Rui Liao (Department of Hepatobiliary Surgery, The First Affiliated \\ Hospital of Chongqing Medical University, Chongqing, China). \\ Comment on: Ventura-Cots M, Watts AE, Cruz-Lemini M, et al. Colder weather and fewer sunlight hours increase alcohol consumption and alcoholic \\ cirrhosis worldwide. Hepatology 2018. [Epub ahead of print].
}

Received: 18 December 2018; Accepted: 20 December 2018; Published: 27 December 2018.

doi: $10.21037 / \operatorname{tgh} .2018 .12 .08$

View this article at: http://dx.doi.org/10.21037/tgh.2018.12.08

As a matter of fact, a prevalence of alcohol misuse can be observed in colder regions at a global scale. As an example, Eastern Europe has the highest annual consumption per capita (15.7 L per person) and North Africa/Middle East has the lowest one (1.0 L per person) (1). However, while numerous confounders such as cultural or religious parameters could explain this difference, no article has already linked climate and alcohol consumption after adjustment for confounders.

To provide scientific evidence of the independent influence of climate on alcohol consumption and alcoholic cirrhosis, the Pittsburgh Liver Research Center performed a large epidemiological study recently published in Hepatology (2). Using data from official sources, such as the World Health Organization, the World Meteorological Organization, and the Institute on Health Metrics and Evaluation, Bataller's group collected the following 2 climatic variables covering 193 countries and the 50 US states: average temperatures and sunlight hours. Alcohol consumption was measured as total alcohol intake per capita and its patterns were assessed by the percent of the population that drinks alcohol and the incidence of binge drinking. After adjustment for potential confounders such as religion or legislation limiting alcohol intake, the authors demonstrated a clear inverse relationship between these 2 climate-related factors and alcohol consumption at a global level. Furthermore, after adjustment for health factors that might exacerbate the effects of alcohol on the liverlike viral hepatitis, obesity or smoking - a potential causal effect of climatic variables on alcohol-attributable fraction of cirrhosis mediated by an increase in alcohol consumption was suggested. Quantitative alcohol consumption was indeed demonstrated to be an independent risk factor for alcohol-attributable fraction of cirrhosis while climatic variables were not. Both trends were observed when comparing across countries but also across counties within the United States.

Several reasons could explain this association between colder and darker regions and alcohol consumption. Primarily, thanks to its vasodilator action, alcohol increases the skin blood flow leading its temperature sensors to produce a heat sensation. Moreover, cold weather and short sunshine periods are known to promote depression, which in turn can cause a significant attraction for alcohol. Lastly, cold regions are likelier to be geographically isolated. Therefore, boredom (or even isolation caused depression) could lead to an alcohol overconsumption. The observations of this study thus raise additional social questions. Grossly, are people in small northern communities drinking because it is cold and dark, or just to break the daily monotony?

Before setting up specifically designed prevention campaigns targeting colder and darker regions' populations, 
further researches seem to be mandatory. These results appear to be conflicting and far from being consensual, especially in Europe: overall, lower alcohol intakes can be observed in Scandinavian countries-such as Norway, Sweden and Finland-as opposed to Spain and Portugal, further south $(3,4)$.

\section{Acknowledgements}

None.

\section{Footnote}

Conflicts of Interest: The author has no conflicts of interest to declare.

doi: $10.21037 /$ tgh.2018.12.08

Cite this article as: Ganne-Carrié N. Alcohol-related liver disease: do weather and daylight level matter or is there a paradoxical good side of global warming? Transl Gastroenterol Hepatol 2018;3:109.

\section{References}

1. Popova S, Rehm J, Patra J, et al. Comparing alcohol consumption in central and eastern Europe to other European countries. Alcohol Alcohol 2007;42:465-73.

2. Ventura-Cots $M$, Watts AE, Cruz-Lemini M, et al. Colder weather and fewer sunlight hours increase alcohol consumption and alcoholic cirrhosis worldwide. Hepatology 2018. [Epub ahead of print].

3. GBD 2016 Alcohol Collaborators. Alcohol use and burden for 195 countries and territories, 1990-2016: a systematic analysis for the Global Burden of Disease Study 2016. Lancet 2018;392:1015-35.

4. Rehm J, Samokhvalov AV, Shield KD. Global burden of alcoholic liver diseases. J Hepatol 2013;59:160-8. 